\title{
"Avoidable" mortality and health services: a review of aggregate data studies
}

\author{
J P Mackenbach, M H Bouvier-Colle, E Jougla
}

\begin{abstract}
Study objective-The aim of the study was to review published work reporting mortality from conditions amenable to medical intervention and compare the methods used and the results obtained.

Source material-Two types of analysis were examined: (1) analyses of time trends, relating decline in mortality from amenable conditions to improvements in medical care ( 3 papers); (2) analyses of geographical variation, either between or within countries, in which mortality was related to the availability of health care resources and to other factors (8 papers).

Results-Time-trend studies have in general shown that mortality from amenable causes has declined faster over the past decades than most other causes of death. Studies of geographical variation have shown that mortality from amenable causes is consistently associated with socioeconomic factors, and that the association with the provision of health care resources is rather weak and inconsistent.

Conclusions-(1) The low levels of mortality from amenable causes which presently prevail in industrialised countries are likely to reflect, at least in part, the increased effectiveness of health services; (2) geographical variation in mortality from amenable causes has not yet been shown to reflect differences in effectiveness of health services; and (3) if geographical variation in avoidable mortality does reflect such differences, they must arise from circumstances other than the level of supply, for example from more specific aspects of health care delivery, and are probably closely related to socioeconomic circumstances. In depth studies at the individual level are now more likely to produce information about factors limiting the effectiveness of health services than further studies of aggregate data.
\end{abstract}

Since 1983 several papers have reported on variation in mortality from conditions amenable to medical intervention ("avoidable" mortality), either over time or between geographical areas. These studies are all based upon two publications by Rutstein et al. ${ }^{12}$ In order to develop indicators of the quality of medical care he drew up a number of lists of diseases which should not, or should only infrequently, give rise to death or disability. This idea has been taken up in studies of mortality variations over time and across geographical areas, at first by Charlton $e$ al $^{3}$ and later by an increasing number of other investigators.

It is indeed tempting to use the geographical variation in mortality from these diseases to pinpoint areas where health service effectiveness may be unsatisfactory: regions or countries with excessive numbers of such "avoidable" deaths could be suspected of having less effective health care. This is the more tempting because data on mortality from amenable conditions are readily available in most industrialised countries, whereas there is no abundance of (other) indicators of the outcome of health services at population level.

This line of reasoning has given rise to a "concerted action" project in the framework of the Health Services Research programme of the European Community (EC). Following the work by Charlton $e t \mathrm{al}^{3}$ a collaborative effort was made to prepare an atlas of avoidable mortality in the European Community. National teams collected data on mortality from selected causes, and supplied them to a coordinating centre at the Department of Community Medicine of United Medical and Dental Schools, St Thomas's Campus, London, UK. For 1974-1978, maps and tables were prepared which were subsequently published in $1988 .^{4}$

Concomitantly, some of the participating teams performed a number of explanatory analyses, especially the teams from Belgium, ${ }^{5}$ France, ${ }^{6}$ England and Wales, ${ }^{3} 78$ and the Netherlands. ${ }^{9-11}$ In addition, research teams not participating in the EC concerted action also contributed a number of explanatory studies, one from England and Wales ${ }^{12}$ and two from Finland. ${ }^{13} 14$ Two types of analysis have been reported:

(1) Analyses of time trends, implicitly relating the decline of mortality from amenable conditions to improvements in medical care. $^{81013}$

(2) Analyses of geographical variation, either between or within countries, in which mortality was related to the provision of health service resources and/or to other factors. $^{35-79111214}$

A main concern in many of these studies is whether rates of mortality from conditions amenable to medical intervention can indeed be interpreted as indicators of the effectiveness of health services.

In order to investigate this, mortality from amenable causes is either implicitly (in the time trend studies) or explicitly (in the geographical variation studies) related to health services. In most studies of geographical variation, sociodemographic variables are used to control for the influence of extraneous factors. 
Although it is impossible with this type of study, referred to as "aggregate data studies", to give a definitive answer to the question whether mortality from amenable causes is an indicator of health service effectiveness, these aggregate data studies have produced a number of interesting findings which will be reviewed here.

In this review we shall first summarise the methods used in these studies, then go on to present the main results, and finally discuss the implications of the findings, both regarding the interpretation of observed trends and differences in avoidable mortality and regarding further research.

\section{Methodology}

Some basic characteristics of the studies reviewed are presented in table I.

\section{INFORMATION USED IN THE ANALYSES} Selection of causes of death

All studies of avoidable mortality reviewed in this paper use a selection of causes of death based

Table I Basic characteristics of the studies reviewed in this paper

\begin{tabular}{|c|c|c|c|c|c|}
\hline \multirow{2}{*}{$\begin{array}{l}\text { First } \\
\text { author }\end{array}$} & \multirow{2}{*}{$\begin{array}{l}\text { Country; } \\
\text { number of } \\
\text { regions }\end{array}$} & \multirow[t]{2}{*}{ Period } & \multirow{2}{*}{$\begin{array}{l}\text { Number } \\
\text { of causes } \\
\text { of death }^{a}\end{array}$} & \multicolumn{2}{|c|}{ Explanatory variables } \\
\hline & & & & $\begin{array}{l}\text { Health } \\
\text { care }\end{array}$ & Other \\
\hline & & \multicolumn{2}{|c|}{ Time trend studies } & & \\
\hline Charlton $^{8}$ & 6 countries & $1950-1980$ & 10 & - & - \\
\hline Mackenbach 10 & Netherlands & $1950-1984$ & 35 & - & - \\
\hline Poikolainen $^{13}$ & Finland & $1969-1981$ & 22 & - & \\
\hline \multicolumn{6}{|c|}{ Studies of geographical variation } \\
\hline Bauer $^{7}$ & $\begin{array}{l}\text { England } \\
\text { and Wales; }\end{array}$ & $1974-1978$ & 13 & - & $\begin{array}{l}\text { Socioeconomic } \\
\text { Disease rates }\end{array}$ \\
\hline Carr-Hill ${ }^{12}$ & $\begin{array}{l}\text { England } \\
\text { and Wales; }\end{array}$ & $1976-1983$ & 4 & Expenditure & Socioeconomic \\
\hline Charlton $^{3}$ & $\begin{array}{l}\text { England } \\
\text { and } W \text { ales; }\end{array}$ & 1974-1978 & 15 & - & Socioeconomic \\
\hline Humblet $^{5}$ & $\begin{array}{l}98 \text { regions } \\
\text { Belgium; } \\
43 \text { regions }\end{array}$ & 1974-1978 & 10 & Use & Socioeconomic \\
\hline Jougla $^{6}$ & France; & 1973-1977 & 11 & Supply, use & Socioeconomic \\
\hline Kunst $^{9}$ & $\begin{array}{l}10 \text { EC } \\
\text { countries; } \\
\text { 8-98 regions }\end{array}$ & 1974-1978 & 12 & Supply & Socioeconomic \\
\hline Mackenbach $^{11}$ & $\begin{array}{l}\text { Netherlands; } \\
28 \text { regions }\end{array}$ & $\begin{array}{l}1950-1954 \\
1960-1964 \\
1970-1974 \\
1980-1984\end{array}$ & 13 & Supply & $\begin{array}{l}\text { Socioeconomic } \\
\text { Urbanisation }\end{array}$ \\
\hline Poikolainen ${ }^{14}$ & $\begin{array}{l}\text { comparison } \\
\text { of } 25 \\
\text { countries }\end{array}$ & $1975-1978$ & $\begin{array}{l}2 \\
\text { broad groups }\end{array}$ & Supply & $\begin{array}{l}\text { Socioeconomic } \\
\text { Risky habits }\end{array}$ \\
\hline
\end{tabular}

anly conditions amenable to medical intervention are counted.

Table II Selection of causes of death in first published study by Charlton ${ }^{3}$

\begin{tabular}{|c|c|c|}
\hline Cause of death & ICD $\operatorname{code}^{2}$ & Age group \\
\hline $\begin{array}{l}\text { Hypertensive disease } \\
\text { Cancer of cervix uteri } \\
\text { Pneumonia and bronchitis } \\
\text { Tuberculosis (excluding silicotuberculosis) } \\
\text { Asthma } \\
\text { Chronic rheumatic heart disease } \\
\text { Acute respiratory disease } \\
\text { Bacterial infections } \\
\text { Hodgkin's disease } \\
\text { Abdominal hernias } \\
\text { Acute and chronic cholecystitis } \\
\text { Appendicitis } \\
\text { Maternal deaths } \\
\text { Deficiency anaemias } \\
\text { Perinatal deaths }\end{array}$ & $\begin{array}{l}400-404 \\
180 \\
480-486,490 \\
011-019 \\
493 \\
393-398 \\
460-466,470-474 \\
\star \\
201 \\
550-553 \\
574-575 \\
540-543 \\
630-678 \\
280-281 \\
-\end{array}$ & $\begin{array}{r}5-64 \\
5-64 \\
5-49 \\
5-64 \\
5-49 \\
5-44 \\
5-49 \\
5-64 \\
5-34 \\
5-64 \\
5-64 \\
5-64 \\
10-44 \\
5-64 \\
-\end{array}$ \\
\hline
\end{tabular}

8th revision

*004, 034, 320, 381-383, 390-392, 680-686, 710, 720. upon Rutstein's lists of “sentinel health events", 12 generally omitting very infrequent causes of death and further omitting those causes for which avoidability lies outside the health care system, such as in many forms of primary prevention. Some studies, however, did analyse mortality from causes amenable to primary prevention, such as traffic accidents and lung cancer. ${ }^{56}$ Because no relationship with health care variables can reasonably be expected, we shall ignore these causes of death in this review.

The first paper on variation in mortality from conditions amenable to medical intervention was published in 1983 by Charlton et $\mathrm{al}^{3}$ and used the selection of causes of death mentioned in table II. Although all these conditions were indeed mentioned by Rutstein (with the exception of chronic rheumatic heart disease) it is not a complete selection. Examples of conditions mentioned by Rutstein et al but not selected by Charlton et al, although related to curative services and with sufficient numbers of deaths, are a number of cancers (larynx, malignant melanoma, body of uterus, neuroblastoma, thyroid, colon and rectum), epilepsy, and peptic ulcer. ${ }^{2}$

It is interesting to see that some of these conditions have been included in a number of later studies. The most extensive additions have been made in two studies of time trends, not requiring a large number of deaths. Mackenbach et $\mathrm{al}^{10}$ and Poikolainen and Eskola ${ }^{13}$ have included a whole series of additional causes of death, not always, however, based upon Rutstein's lists. Chronic non-specific lung disease was included by Poikolainen and Eskola but not by Rutstein et al. Prostate hyperplasia, nephritis/nephrosis and cancer of testis were included by Mackenbach $e t$ al but not by Rutstein et al. Cerebrovascular disease was included in many studies, although Rutstein et al only mentioned "vascular complications of heart or brain associated with hypertensive disease". 2

Frequently, the studies reviewed here also omit some causes of death from the selection proposed by Charlton et al. ${ }^{3}$ This may be because of insufficient numbers of deaths in some countries or because of unavailability of data, but it may also reflect difference of opinion on the possible influence of health care on mortality. Unfortunately, a specific discussion of reasons for including or excluding causes of death is almost always lacking.

\section{Health care variables}

The health care variables used in the geographical variation studies were generally rather crude indicators of supply or use of health care resources. In some cases indicators of the technical level of the supply of health care were included, for example, by Humblet $e t a l^{5}$ in the form of an index of technicality, and by Mackenbach $e t a l^{11}$ in the form of a measure for the presence of a teaching hospital.

Because of the strong intercorrelations within a larger set of health care variables, Jougla et al $^{6}$ performed a factor analysis (principal component analysis) of these variables. They derived three new explanatory variables, each indicating a different aspect of the health care system. 
Sociodemographic and other variables

When relating mortality to health care variables, it is necessary to control for the confounding effect of extraneous factors. Most authors use sociodemographic variables to this purpose Indicators of socioeconomic circumstances (eg, unskilled workers, households renting, car ownership, unemployment, income etc) are most frequently used. Sometimes other sociodemographic factors are included, eg, urbanisation. Only in the study of international variation by Poikolainen and Eskola ${ }^{14}$ were more direct measures of the risk of mortality used as control variables in the analysis, namely smoking and alcohol consumption.

In the study by Bauer and Charlton ${ }^{7}$ measures of disease incidence (hospital admission rates, cancer incidence rates, disease notification rates) have been used to study the relationship between mortality and incidence of the same conditions; variations in incidence were considered to be due to extraneous factors, ie, not to variations in effectiveness of health services.

STATISTICAL METHODS

Derivation of a mortality measure

Various standardisation procedures have been used to remove the influence of differences in age structure between populations. Only Poikolainen and Eskola ${ }^{13}$ used unstandardised death rates, because a comparison with standardised death rates showed no substantial differences.

In the studies of geographical variation the standardised mortality ratio (SMR) is the most frequently employed measure. Sometimes logarithmic transformations are used to normalise the distribution of SMRs, for example by Mackenbach et al. ${ }^{11}$

In the paper by Humblet et $a l^{5}$ the dependent variables in the regression analysis are not SMRs (considered insufficiently reliable for small geographical areas), but factorial scores resulting from a preliminary multiple correspondence analysis.

Statistical analysis of the relation between avoidable mortality and health care variables

In most geographical studies, multiple linear regressions (frequently step by step regressions) are used to analyse the association of health care variables with mortality data (SMRs). Sociodemographic and sometimes other factors are introduced as confounding variables. However, some studies display specific methodological characteristics in this respect.

One problem in applying multiple regression to geographical variation in mortality is that the areas may vary considerably in size of population

Table III Summary of results from time trend studies

\begin{tabular}{|c|c|c|c|c|}
\hline \multirow[t]{3}{*}{ Study } & \multicolumn{4}{|c|}{ Per cent per annum mortality change } \\
\hline & \multicolumn{2}{|c|}{ Amenable causes $^{\mathrm{a}}$} & \multicolumn{2}{|c|}{ Non-amenable causes ${ }^{b}$} \\
\hline & Males & Fermales & Males & Females \\
\hline $\begin{array}{l}\text { Charlton } 8 \mathrm{c} \\
\text { Mackenbach } \\
\text { Poikolainen }\end{array}$ & $\begin{array}{l}-6 \\
-8\end{array}$ & $\begin{array}{l}-6 \\
-10\end{array}$ & $\begin{array}{r}0 \\
-2\end{array}$ & $\begin{array}{l}-2 \\
-3\end{array}$ \\
\hline
\end{tabular}

and number of deaths involved. To take account of the variations in population size, Charlton et $a^{3}$ and Bauer and Charlton ${ }^{7}$ used the method of interactively reweighted least squares. Mackenbach et al $^{13}$ performed a fully weighted regression (weights inversely proportional to the variance of the SMRs).

Charlton et $a l^{3}$ did not include health care variables in their multivariate analysis. They performed regressions of mortality data on social factors and interpreted the residuals from such regressions as mortality standardised for social factors. They then compared mortality differences among areas before and after standardisation and considered that if adjustment for social factors failed to alter the pattern of mortality variations, this suggested that health care variables were involved in these differences.

Mackenbach et al took into account the time dependency of the relationship between health care and mortality ${ }^{11}$ by performing four different analyses for four moments in time, considering that it is essentially during the introduction period of medical innovations that this relation should appear clearly.

\section{Results}

TIME TREND STUDIES

The three studies of time trends in mortality from conditions amenable to medical intervention all showed considerable declines for most or all of these conditions in recent decades.

In the international study by Charlton and Velez ${ }^{8}$ these declines were observed in all six countries (England and Wales, Sweden, Italy, France, United States of America and Japan). According to the authors, this consistency in mortality trends between countries differing in social, environmental, genetic and diagnostic factors suggests that improvements in health care were a factor in the decline.

Rapid declines in mortality from amenable causes were also observed in Finland ${ }^{13}$ and the Netherlands. ${ }^{10}$ In the study from the Netherlands two time periods were compared: $1950-1968$ and 1969-1984. Mortality declined for almost all of the 35 selected conditions, both in the first and in the second time period. For some conditions, for example many infectious diseases amenable to antibiotic treatment and infectious diseases preventable by vaccination, mortality declines were steepest in the first time period, which corresponds with the moment of introduction of these innovations. The same applies to most of the conditions for which the decline was steepest in the second time period, for example cerebrovascular disease, perinatal mortality, certain congenital anomalies, Hodgkin's disease and cancer of the cervix. This suggests that the declines were due at least in part to the introduction of effective medical interventions.

All three studies stress the fact that declines in mortality from amenable conditions may not be due entirely to better health care. Socioeconomic conditions have also been improving, and for a number of amenable conditions "spontaneous" declines in incidence have been observed. In order to account for the confounding effect of these spontaneous improvements, all three 
studies have compared trends in mortality from amenable conditions with trends in mortality from other conditions. The results are summarised in table III.

The table presents simple averages of values reported for many causes of death, and because selections of causes of death and time periods differed between studies, the results of different studies cannot be compared directly. What is evident, however, is the fact that mortality from non-amenable causes declined much less than mortality from amenable causes in all three studies.

All authors suggest that this supports the idea that at least part of the mortality decline for amenable conditions is due to improvements in health care. Poikolainen and Eskola ${ }^{13}$ even take the difference in mortality decline between amenable and non-amenable conditions as an approximation of the "true" effect of better health care.

STUDIES OF GEOGRAPHICAL VARIATION Relationship between avoidable mortality and health care resources

Table IV summarises the results of the studies of geographical variation in avoidable mortality, as far as the associations with health care variables are concerned.

These associations are only infrequently statistically significant. This is true, for example, for France, where Jougla et $a l^{6}$ studied 60 associations (11 causes, for one or both sexes, $v$ three health care indices) and found only 10 to be statistically significant at the 5\% level. Kunst et $a l^{9}$ found 78 negative associations within EC

Table IV Summary of results from studies of geographical variation: associations between avoidable mortality and health care resources, controlling for sociodemographic and other variables

\begin{tabular}{|c|c|c|c|c|c|c|}
\hline \multirow[t]{2}{*}{ Study } & \multicolumn{3}{|c|}{$\begin{array}{l}\text { Number of associations } \\
\text { studied }\end{array}$} & \multicolumn{3}{|c|}{$\begin{array}{l}\text { Number of statistically } \\
\text { significant associations } \mathrm{bc}\end{array}$} \\
\hline & Total & Positive & Negative & Total & Positive & Negative \\
\hline $\begin{array}{l}\text { Bauer }^{7} \\
\text { Carr-Hill }^{12} \\
\text { Charlton }^{3} \\
\text { Humblet }^{5} \\
\text { Jougla }^{6} \\
\text { Kunst }^{9} \\
\text { Mackenbach }^{11} \text { d } \\
\text { Poikolainen }^{14}\end{array}$ & $\begin{array}{l}\text { na } \\
(32) \\
\text { na } \\
6 \\
60 \\
137 \\
43 \\
6\end{array}$ & $\begin{array}{l}\text { na } \\
(24) \\
\text { na } \\
3 \\
\ldots \ldots \\
59 \\
18 \\
4\end{array}$ & $\begin{array}{c}\mathrm{na} \\
(8) \\
\mathrm{na} \\
3 \\
\ldots 8 \\
78 \\
25 \\
2\end{array}$ & $\begin{array}{l}\text { na } \\
\ldots \\
\text { na } \\
2 \\
10 \\
\ldots \\
4 \\
0\end{array}$ & $\begin{array}{l}\text { na } \\
\ldots \ldots \\
\text { na } \\
1 \\
5 \\
\ldots \\
2 \\
0\end{array}$ & $\begin{array}{l}\text { na } \\
\ldots \ldots \\
\text { na } \\
\cdot 1 \\
5 \\
12 \\
2 \\
0\end{array}$ \\
\hline
\end{tabular}

na = not applicable; $\ldots$. . = not reported; ( ) without control for sociodemographic factors a $=$ not applicable $\ldots \ldots=$ not reported; $($ without control for sociodemographic factors b Only avoidable causes counted

c $\alpha=0.05$

$\alpha=0.05$
Associations reported for 1980-1984; for the variable "small hospitals" a positive association is counted as a negative one and vice versa

Table $V$ Summary of results from studies of geographical variation: association between avoidable mortality and socioeconomic factors ${ }^{a}$

\begin{tabular}{|c|c|c|c|c|c|c|}
\hline \multirow[t]{2}{*}{ Study } & \multicolumn{3}{|c|}{$\begin{array}{l}\text { Number of associations } \\
\text { studied }\end{array}$} & \multicolumn{3}{|c|}{$\begin{array}{l}\text { Number of statistically } \\
\text { significant associations }\end{array}$} \\
\hline & Total & Positive & Negative & Total & Positive & Negative \\
\hline $\begin{array}{l}\text { Bauer }^{7} \\
\text { Carr-Hill }^{12} \\
\text { Charlton }^{3} \\
\text { Humblet }^{5} \\
\text { Jougla }^{6} \\
\text { Kunst }^{9} \\
\text { Mackenbach }^{11} \\
\text { Poikolainen }^{14}\end{array}$ & $\begin{array}{c}\text { replica } \\
(8) \\
(45) \\
(6) \\
60 \\
\ldots \ldots \\
\ldots . \\
2\end{array}$ & $\begin{array}{l}\text { of Charlt } \\
\text { (0) } \\
(3) \\
(4) \\
\ldots \ldots \\
\ldots \ldots \\
\ldots\end{array}$ & $\begin{array}{r}2^{3} \\
(8) \\
(42) \\
(2) \\
\cdots \cdots \\
\cdots \cdots \\
\cdots\end{array}$ & $\begin{array}{c}(22) \\
(2) \\
20 \\
\ldots \ldots \\
\ldots \\
2\end{array}$ & $\begin{array}{c}(3) \\
(0) \\
4 \\
\cdots \\
0\end{array}$ & $\begin{array}{c}(19) \\
(2) \\
16 \\
\ldots \ldots \\
\ldots \\
2\end{array}$ \\
\hline
\end{tabular}

= not reported; ( ) without control for health care variables

a "negative" association implies higher mortality in "worse" socioeconomic circumstances Only avoidable causes counted

c $\alpha=0.05$ countries of which only 12 were statistically significant. For the Netherlands in 1980-84 only two out of 25 negative associations were statistically significant. ${ }^{11}$

In general, one would have expected the associations between avoidable mortality and health care resources to be negative, implying lower mortality in regions with a larger supply or use of health care services. A predominance of negative associations is, however, not evident at all. Carr-Hill et al ${ }^{12}$ calculated simple correlations between mortality from four conditions amenable to medical intervention and four indicators of health care resources for regional health authorities in England and Wales. They found most of them to be positive, more so in 1983 than in 1976. It should be noted, however, that there was no control for possible confounding variables in this analysis. For Belgium, Humblet et $a l^{5}$ found both positive and negative associations, after controlling for socioeconomic variables. The same applies to France. ${ }^{6}$ It is only in the studies by Kunst et $a l^{9}$ and Mackenbach et al ${ }^{11}$ that negative associations are slightly more frequent than positive ones. In their study of regional variation in EC countries in 1974-78, Kunst et al found that, after controlling for socioeconomic variables, negative associations were more frequent in some countries (eg, Italy, England and Wales) than in others (eg, France). For the Netherlands in 1980-84 associations were also slightly more frequently in the expected direction. A comparison of associations in four time periods (1950-54, 1960-64, 1970-74, 1980-84) showed that the percentage of variance "explained" by health care variables changed over time. The authors' hypothesis that for each cause of death the association with health care variables was strongest during the period of introduction of effective medical interventions could not, however, be confirmed. ${ }^{11}$

Poikolainen and Eskola's study of international variation, finally, did not find statistically significant associations between mortality from amenable causes and the supply of health care, after controlling for socioeconomic measures such as the gross domestic product. ${ }^{14}$ Both for men and women, the associations with the supply of doctors and nurses tended to be positive.

When one compares the findings of the different studies there does not appear to be a systematic pattern in the combinations of causes of death and health care variables for which statistically significant associations did emerge. In France, for example, the only negative association with the health care index representing supply of doctors and hospital beds was found for influenza. In addition, negative associations with the index representing the presence of a top level hospital (Centre Hospitalier Régional) were found for chronic rheumatic heart disease and hypertensive disease. ${ }^{6}$ In the Netherlands, however, there was no statistically significant associations between mortality from amenable causes and the supply of general practitioners or hospital beds in 1980-84. There were some negative associations with the presence of a university hospital, but these were found for "surgical" conditions and for cerebrovascular disease. ${ }^{11}$ 
Relationship between avoidable mortality and other variables

The associations between mortality from conditions amenable to medical intervention and socioeconomic factors are considerably stronger and much more consistent than those with health care resources (table $\mathrm{V}$ ). These associations were already studied extensively in the first paper on regional variation in avoidable mortality by Charlton et al. ${ }^{3}$ They found that in England and Wales in 1974-78 mortality from almost all amenable conditions was higher in areas characterised by less favourable socioeconomic conditions. It was only for Hodgkin's disease that the associations with three socioeconomic indicators were in the opposite direction. These findings have been replicated in many other studies, including those by Carr-Hill et al for regional health authorities in England and Wales, ${ }^{12}$ by Jougla et al for French "départements", 6 and by Poikolainen and Eskola for 25 countries. ${ }^{14}$ Humblet et al, on the other hand, found more positive associations for Belgian "arrondissements", although only the negative ones were statistically significant."

Although Kunst et al did not give a detailed report on the nature of the associations between mortality from amenable causes and socioeconomic factors in various EC countries, they did show the percentage of variance explained by these factors in England and Wales, Italy and France. $^{9}$ This was sometimes considerable, and mostly larger than the percentage variance explained by health care variables.

In the study by Bauer and Charlton ${ }^{7}$ the associations between mortality from amenable causes and socioeconomic factors are the same as those reported by Charlton et al. ${ }^{3}$ This study adds an analysis of the contribution of differences in incidence, as measured by hospital discharges, cancer registration and disease notification. The results suggest that differences in morbidity, ie, factors other than health service effectiveness, do account for part of the variation in mortality, although some heterogeneity persists after morbidity and socioeconomic factors have been taken into account.

\section{Discussion}

One of the most remarkable observations in this review is that there is a large amount of variation in methodology between studies of avoidable mortality. Although all studies are based upon Rutstein's original publications, and most investigators cooperate in a European Community concerted action, the selections of causes of death, the methods of analysis, and the selections of explanatory and confounding variables differ substantially.

To a large extent this variation simply reflects local circumstances with respect to availability of data both on mortality and on other variables. On the other hand, it also discloses some divergence of opinion on, for example, the evidence concerning avoidability of death for certain conditions. This is probably related to the informal character of the process of selection of causes of death. The lists published by Rutstein $e t$ al have been prepared by a working group which has not documented its choice of conditions with a detailed review of available evidence. The same applies to most of the studies reviewed here, although in some of these references are given for each of the selected conditions. ${ }^{341013}$ Unfortunately, explicit criteria for judging the evidence on increased effectiveness of medical interventions (eg, regarding the internal and external validity of evaluation studies and regarding the size of the estimated effect) are lacking completely. An important suggestion for further work might thus be to document more fully the selection of causes of death to be included in this type of study, preferably using formal synthesis methods.

Whereas the variation in selections of diseases, methods of analysis, and selections of variables may be seen as a weakness of this field of research, it also has an advantage. All studies of time trends show important mortality declines, and all studies of regional variation show large differences in mortality as well as rather strong and consistently negative associations with socioeconomic variables, regardless of the specific features of the analysis. None of the geographical studies shows convincing associations with health care variables. These general findings are clearly not dependent on the methodology used, which raises confidence that they reflect reality.

What do the findings imply for the validity of mortality rates for conditions amenable to medical intervention as indicators of the effectiveness of health care services? The findings of the time trend studies suggest that the low levels of mortality from these conditions which presently prevail in industrialised countries are due, at least in part, to the increased effectiveness of health care services. The declines have been observed in many countries, and have been faster than the declines in mortality for other conditions. The timing of the declines also suggests that they were related to the introduction of specific improvements in health care. This does not, however, imply that regional variation in the remaining mortality from these conditions is due to variation in the effectiveness of health care services. It is perfectly possible that this variation simply reflects "spontaneous" variation in incidence or severity of these conditions. Thus the study by Bauer and Charlton ${ }^{7}$ suggests that differences in incidence do account for at least part of the mortality variation.

The associations with health care variables in the geographical studies can be characterised as weak and inconsistent. If they had been stronger and more consistent, this could have been interpreted as evidence that mortality from conditions amenable to medical intervention reflects differences in effectiveness of health care services. Now that this is not the case, the interpretation is much less straightforward. Most authors agree that the absence of a clear pattern of negative associations between health care variables and avoidable mortality rates is no proof that the latter are invalid as indicators of the effectiveness of health care services. Two types of argument are offered for this.

The first is that the health care variables used to "explain" the mortality variation were generally 
rather crude measures of supply or use of health care services, sometimes complemented by a measure of the availability of high level hospital care. It is possible that the way in which this supply is organised, made to conform to quality standards, and made accessible to the population is more important for the prevention of "avoidable" deaths than the level of supply per se, and that these factors vary across regions independently from the level of supply. 911 This would imply that a validation of avoidable mortality rates as indicators of the effectiveness of health care services should make use of measures of more specific aspects of health care delivery.

The second argument is that levels of supply may in part reflect allocation decisions based upon observed differences in mortality (or demand, following from underlying morbidity differences). This argument would seem to apply more specifically to England and Wales, where budgets are allocated to regions according to a formula incorporating mortality measures. ${ }^{12} \mathrm{On}$ the other hand, the same argument has also been offered for Belgium in the statement that mortality is not only an indicator of outcome but also an indicator of need. ${ }^{5}$

Whatever one's interpretation of the findings, the main conclusion is that the studies of geographical variation have not provided evidence that varying rates of mortality from conditions amenable to medical intervention reflect variation in effectiveness of health care services. The validity of these indicators thus remains to be proven. It is clear, on the other hand, that if differences in effectiveness of health services are implied the latter arise from other circumstances than the level of supply, for example more specific aspects of health care delivery, and are probably closely related to socioeconomic circumstances.

We suggest that further research should leave the realm of aggregate data studies and should investigate individual deaths from amenable conditions in an attempt to see whether they can be linked to deficiencies in the organisation, quality or accessibility of health care services. There is an important tradition for this type of study in the field of maternal and perinatal mortality, where confidential enquiries have been used to obtain detailed information on the care received by the deceased. This approach is probably also feasible for other causes of death, as is evident from recent studies of perioperative deaths and asthma deaths. Local "avoidable factors" in health care services may be found to have a substantial impact on the incidence of deaths from these causes. One of the main uses of aggregate data on avoidable mortality would then be the identification of "hot spots" of avoidable mortality, where further investigation promises high rewards. ${ }^{15}$

Detailed tables comparing the studies reviewed in this paper are available on request from JPM.

1 Rutstein DD, Berenberg W, Chalmers TC, Child CG, Fishman AP, Perrin EB. Measuring the quality of medical care. N Engl I Med 1976; 294: 582-8.

2 Rutstein DD, Berenberg W, Chalmers TC, Child CG, Fishman AP, Perrin EB. Measuring the quality of medical care, second revision of tables of indexes. $N$ Engl $\mathcal{F}$ Med 1980; 302: 1146-50.

3 Charlton JRH, Hartley RM, Silver R, Holland WW. Geographical variation in mortality from conditions amenable to medical intervention in England and Wales. amenable to medical inte

4 EC Working Party on Health Services and Avoidable Mortality. European community atlas of avoidable death. London: Oxford Medical Publications, Health Services Research Series No. 3, 1988.

5 Humblet PC, Lagasse R, Moens GFG, Wollast E, van de Voorde H. La mortalité évitable en Belgique. Soc Sci Med 1987; 25: 485-93.

6 Jougla E, Ducimétière P, Bouvier-Colle MH, Hatton F. Relation entre le niveau de développement du système de soins et le niveau de la mortalité "évitable" selon les départements français. Rev Epidémiol Santé Publ 1987; 35: 365-77.

7 Bauer RL, Charlton JR. Area variation in mortality from diseases amenable to medical intervention: the contribution of differences in morbidity. Int $\mathcal{f}$ Epidemiol 1986; 15: 408-12.

8 Charlton JRH, Velez R. Some international comparisons of mortality amenable to medical intervention. Br Med $\mathcal{f} 1986$; 292: 295-301.

9 Kunst AE, Looman CWN, Mackenbach JP. Medical care and regional mortality differences within the countries of the European Community. Eur $f$ Population 1988; 4: 223-45.

10 Mackenbach JP, Looman CWN, Kunst AE, Habbema JDF, van der Maas PJ. Post-1950 mortality trends and medical care: gains in life expectancy due to declines in mortality from conditions amenable to medical intervention. $S o c S c i$ Med 1988; 27: 889-94.

11 Mackenbach JP, Kunst AE, Looman CWN, Habbema JDF, van der Maas PJ. Regional differences in mortality from conditions amenable to medical intervention in The Netherlands: a comparison of 4 time-periods. $\mathcal{f}$ Epidemiol Community Health 1988; 42: 325-32.

12 Carr-Hill RA, Hardman GF, Russsell IT. Variations in avoidable mortality and variations in health care resources. avoidable mortality and

13 Poikolainen K, Eskola J. The effect of health services on mortality: decline in death rates from amenable and nonamenable

14 Poikolainen K, Eskola J. Health services resources and their relation to mortality from causes amenable to health care intervention: a cross-national study. Int $\mathcal{F}$ Epidemiol 1988; 17: 86-9.

15 Holland WW. The "avoidable death" guide to Europe. Health Policy 1986; 6: 115-7. 